\title{
Ethnic differences in dietary intake at age 12 and 18 months: the Born in Bradford 1000 Study
}

\author{
Pinki Sahota ${ }^{1, *}$, Lisa A Gatenby ${ }^{2}$, Darren C Greenwood ${ }^{3}$, Maria Bryant $^{4}$, Sian Robinson ${ }^{5}$ \\ and John Wright ${ }^{6}$ \\ 'Institute for Health \& Wellbeing, Faculty of Health and Social Sciences, Leeds Metropolitan University, City Campus, \\ Calverley Street, Leeds LS1 3HE, UK: ${ }^{2}$ Sport, Health, Nutrition, Leeds Trinity University, Leeds, UK: ${ }^{3}$ Division of \\ Biostatistics, University of Leeds, Leeds, UK: ${ }^{4}$ Leeds Institute for Clinical Trials Research, University of Leeds, Leeds, \\ UK: ${ }^{5}$ MRC Lifecourse Epidemiology Unit, University of Southampton, Southampton, UK: Institute of Health Research, \\ Bradford Teaching Hospitals NHS Trust, Bradford, UK
}

Submitted 4 July 2014: Final revision received 8 February 2015: Accepted 11 February 2015: First published online 24 April 2015

\begin{abstract}
Objective: To compare the intake of key indicator foods at age 12 months and 18 months between infants of Pakistani and White British origin.

Design: Logistic regression was used to model associations between ethnicity and consumption of key indicator foods defined by high or low energy density using an FFQ at age 12 and 18 months.

Setting: Born in Bradford 1000 study, Bradford, UK.

Subjects: Infants ( $n$ 1259; $38 \%$ White British, 49\% Pakistani), mean age 12.7 (sD 1.0) months and toddlers ( $n$ 1257; $37 \%$ White British, $49 \%$ Pakistani), mean age $18 \cdot 7(\mathrm{sD} 1 \cdot 0)$ months.

Results: At 12 months, Pakistani infants consumed more commercial sweet baby meals than White British infants, with greater odds for being above average consumers (adjusted OR $(\mathrm{AOR})=1.90 ; 95 \%$ CI 1.40, 2.56), more chips/roast potatoes $(\mathrm{AOR}=2.75 ; 95 \% \mathrm{CI} 2.09,3.62)$, less processed meat products $(\mathrm{AOR}=0 \cdot 11 ; 95 \% \mathrm{CI} 0 \cdot 08,0 \cdot 15)$, more fruit $(\mathrm{AOR}=2 \cdot 20 ; 95 \% \mathrm{CI} 1 \cdot 70,2 \cdot 85)$ and more sugar-sweetened drinks (AOR =1.68; $95 \%$ CI 1.29, 2·18). At 18 months these differences persisted, with Pakistani infants consuming more commercial sweet baby meals $(\mathrm{AOR}=4.57 ; 95 \%$ CI 2.49, 8.39), more chips/roast potato shapes $(\mathrm{AOR}=2 \cdot 26 ; 95 \% \mathrm{CI} 1 \cdot 50,3 \cdot 43)$, more fruit $(\mathrm{AOR}=1 \cdot 40 ; 95 \% \mathrm{CI} 1 \cdot 08,1 \cdot 81)$, more sugar-sweetened drinks ( $\mathrm{AOR}=2.03 ; 95 \% \mathrm{CI} 1.53,2.70)$, more pure fruit juice $(\mathrm{AOR}=1 \cdot 82 ; 95 \% \mathrm{CI} 1 \cdot 40,2 \cdot 35)$, more water $(\mathrm{AOR}=3 \cdot 24 ; 95 \% \mathrm{CI} 2 \cdot 46,4.25)$ and less processed meat (AOR $=0 \cdot 10 ; 95 \%$ CI 0.06, 0.15) than White British infants. Conclusions: Dietary intake during infancy and the early toddlerhood period is associated with ethnicity, suggesting the importance of early and culturally adapted interventions aimed at establishing healthy eating behaviours.
\end{abstract}

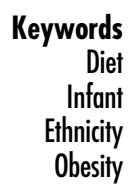

Childhood obesity is a growing problem internationally ${ }^{(1,2)}$. Within the UK, over a fifth of children starting school are overweight or obese and it is estimated that by 2020, 20\% of all boys and $33 \%$ of all girls will be obese ${ }^{(3)}$. Although recent indications are that prevalence is levelling off in 4- to 5-year-olds in the UK, it still remains high and of concern across other ages and certain ethnic groups ${ }^{(4)}$. The prevalence of obesity is significantly higher in children of South Asian origin in the UK compared with White British children $^{(4,5)}$ and people of South Asian origin are also at greater risk of obesity-related conditions such as type 2 diabetes and hypertension ${ }^{(6)}$.

Early childhood provides a unique opportunity to promote health and prevent obesity ${ }^{(7)}$. It has been suggested that dietary patterns emerge early ${ }^{(8)}$ and track through infancy $^{(9)}$ into later childhood ${ }^{(10)}$ and from childhood to adulthood $^{(11)}$. The diet of infants and toddlers has shortand long-term implications for health and development ${ }^{(12)}$. It is therefore important to be able to characterize early-life dietary intake, including understanding the influence of ethnicity on early diet, in order to examine how early diet influences later health outcomes including weight in childhood across diverse ethnic groups.

Inappropriate early dietary patterns that are established during the complementary feeding period (weaning) may persist into the second year of life and beyond ${ }^{(13,14)}$ and therefore optimizing a child's diet before the age of 2 years may be critical in preventing obesity-related disease ${ }^{(15)}$. 
However, there is increasing consensus that many children consume inappropriate foods, consume food in excess of their energy requirements and that inappropriate foods are increasingly being introduced during infancy. A US survey of the diets of a national sample of infants and toddlers ${ }^{(16)}$ showed that high-salt fast foods and high-sugar snacks and drinks were commonly consumed by infants. Energy intake in infants aged 7-11 months exceeded requirements by $23 \%$ and in 1- to 2-year-olds by $30 \%$. In addition, fruit and vegetable consumption was low reflecting a similar pattern to that observed in adults. Data from the Avon Longitudinal Study of Pregnancy and Childhood (ALSPAC) confirmed that such eating patterns are also a problem in the UK and that infants of mothers of lower education were more likely to have fizzy drinks and more likely to drink from a bottle rather than from a cup, both of which have been associated with later obesity ${ }^{(17)}$.

Latest UK data from the Diet and Nutrition Survey Infants and Young Children aged 4 to 18 months ${ }^{(18)}$ reported that infants consumed a varied diet and dietary recommendations were generally met by the majority of the population. The mean total fruit and vegetable consumption, including contribution from mixed dishes, was relatively high. However, consumption of fruit and vegetables was significantly lower in children of South Asian and 'other' ethnicity compared with White children aged 4-18 months ${ }^{(18)}$. Although that survey provides a useful snapshot of the dietary intake of a representative sample of infants within the UK, there is generally limited information from ethnically diverse populations. This information is required to understand the ethnically specific early dietary risk factors associated with the development of obesity in order to inform interventions aimed at establishing healthy eating behaviours.

In light of the influence of early feeding patterns on health outcomes, it is important to explore current infant dietary intakes within populations who are at increased risk for the development of obesity and other co-morbid conditions. The present study aimed to explore the dietary intake of key indicator foods at age 12 and 18 months and to identify any differences between White British and Pakistani populations. In the present study, key indicator foods are defined as those consumed by this age group as identified through dietary surveys and associated with high energy density (high fat, high sugar) and low energy density (high fibre, low fat, low sugar), and therefore assumed to have a plausible role in obesity development.

\section{Methods}

\section{Participants and study design}

The Born in Bradford (BiB) study is a longitudinal, multiethnic birth cohort study designed to examine the impact of environmental, psychological and genetic factors on maternal and child health and well-being ${ }^{(19)}$. Bradford is a city in the north of England with high levels of socioeconomic deprivation and ethnic diversity. Approximately half the births in Bradford are to mothers of South Asian origin. Women were recruited while waiting for their glucose tolerance test, a routine procedure offered to all pregnant women registered at the Bradford Royal Infirmary, at 26-28 weeks' gestation. The $\mathrm{BiB}$ cohort recruited 12453 women comprising 13776 pregnancies between 2007 and 2010, and the cohort is broadly characteristic of the city's maternal population. Ethical approval was granted by Bradford Research Ethics Committee (Ref 07/ H1302/112) and all participants provided written informed consent (including allowing access to routine data collection) prior to inclusion in the research.

A sub-sample of the BiB cohort, the Born in Bradford 1000 cohort (BiB1000), recruited between August 2008 and March 2009, were invited to participate in more detailed follow-up ${ }^{(20)}$. This study involved further assessments at about 6, 12, 18, 24 and 36 months of age, including detailed measurement of anthropometry and social, behavioural and environmental factors that were hypothesized to relate to obesity development ${ }^{(21)}$. Dietary data were collected when infants were aged 12 and 18 months.

Of 1916 mothers eligible for BiB1000, 1735 agreed to take part (91\%). For the current study, participants were excluded if they had multiple births ( $n$ 28) or missing obstetric ( $n$ 42), covariate ( $n$ 137) or infant feeding ( $n$ 269) data. The sample therefore consists of 1259 singleton infants whose mothers had completed the FFQ at 12 months post birth. Of the 1259 singleton infants in the 12-month data, 1081 (86\%) also provided data at 18 months. There were 176 infants who provided 18-month data who had not done so at 12 months, so the final sample of 18 -month-olds comprised 1257 singleton infants.

\section{Measurements}

\section{Dietary intake}

Dietary data were collected when infants were aged 12 and 18 months using a validated FFQ designed to assess infant diet from the Southampton Women's Survey cohort study $^{(22)}$, which was adapted for the BiB1000 cohort. Eight additional items (chapattis (white flour), chapattis (wholemeal flour), boiled rice, fried rice, semolina pudding, milk-based puddings, sponge puddings and other vegetables (e.g. okra, aubergine)) were included to reflect dietary intake within the multi-ethnic population of Bradford, based on findings from focus groups and $24 \mathrm{~h}$ dietary recalls in the area. The resulting FFQ included a list of ninety-eight food items which allowed the frequency of consumption and amounts consumed over the preceding month to be recorded. The response categories included 'never' (record as 0), 'less than once a week' (record as $0 \cdot 5$ ), 'food was eaten weekly' (record number of times per 
Table 1 List of key indicator food groups and categorizations of consumption

\begin{tabular}{ll}
\hline Key indicator food group & Categorization \\
\hline Baby formula milk (incl. all formula milk drinks) & Consumer/non-consumer \\
Baby savoury commercial foods (incl. dried, jars, tinned varieties) & Consumer/non-consumer \\
Baby sweet commercial foods (incl. dried, jars, tinned varieties) & Consumer/non-consumer \\
Chips, roast and potato shapes & $\leq$ Median/>median \\
Processed meat products & $\leq$ Median/ $/>$ median \\
Vegetables (incl. tinned and salad) & $\leq$ Median/ $>$ median \\
Fruit (incl. fresh, tinned and cooked fruit) & $\leq$ Median/>median \\
Sweet snacks (incl. cakes, biscuits, chocolate, sweets) & $\leq$ Median/ $/>$ median \\
Savoury crisp-type snacks & $\leq$ Median/ $>$ median \\
Sugar-sweetened drinks & Consumer/non-consumer \\
Pure fruit juices and baby fruit juices & $\leq$ Median/>median \\
Low-sugar drinks (artificially sweetened) & Consumer/non-consumer \\
Water & $\leq$ Median/>median \\
\hline
\end{tabular}

week) and 'food is eaten more than once a day' (record how many times per day). At the end of each FFQ, an open section in the same format was included to record frequencies of consumption and amounts of any foods that were not listed on the FFQ, if they were consumed once per week or more. Flash cards were used to show the foods included in each food group, to ensure standardized responses to the FFQ. Household utensils (tablespoons, teaspoons, bowls and feeding beakers) were used in estimating portion sizes and quantities of foods and drinks consumed. A team of multilingual community research administrators were trained by dietitians to administer the FFQ. Key indicator food group variables were derived from the FFQ data by a dietitian (P.S.) by grouping similar types of foods from the FFQ within categories associated with high energy density (high fat, high sugar) and low energy density (high fibre, low sugar, low fat). The key indicator foods were selected on the basis of their contribution to dietary patterns associated with the development of obesity. Key indicator food groups used in analysis are listed in Table 1.

\section{Ethnicity}

Ethnicity was self-assigned by the mother and the infant was assigned the same ethnicity at the baseline questionnaire (26-28 weeks' gestation) using the same ethnic group classification as the 2001 UK census ${ }^{(23)}$ and categorized into White British, Pakistani, Other South Asian (Indian, Bangladeshi and other South Asian) and Other ethnicities (White other, Black, mixed race, other unspecified). Due to the smaller numbers within the other ethnic groups in the sample, data are presented for the two larger groups at 12 months (White British (38\%) and Pakistani (49\%)) and at 18 months (White British (37\%) and Pakistani (49\%)).

\section{Data analysis}

The frequency of consumption of key indicator foods by infants at 12 months (White British and Pakistani, $n$ 1092) and 18 months (White British and Pakistani, $n$ 1087) was tabulated across the full cohort and by ethnic group.
Quantitative dietary guidelines do not currently exist for the key indicator foods for this age group in the UK, so it was not possible to categorize intake into those meeting or not meeting recommended intake levels. A pragmatic approach to defining cut-offs has been used to define high and low intakes due to the lack of guidelines for this age group. Therefore, intake data were dichotomized into either consumer/non-consumer (i.e. zero intake/any intake) or below and equal to/above the median intake for that key indicator food group (i.e. lower intake/higher intake); see Table 1.

Logistic regression was used to model associations between ethnicity and infant consumption of key indicator food groups at age 12 and 18 months. Odds ratios for the key indicator foods and differences for intakes with 95\% confidence intervals are presented for Pakistani compared with White British cohort members, adjusted for mother's and father's highest educational qualification and mother's age at the 12-month or 18-month follow-up questionnaire. The statistical software packages Stata release 12.0 (2011) and SAS version $9 \cdot 2$ (2008) were used for all analyses.

\section{Results}

\section{Characteristics of the sample}

Table 2 provides information on the characteristics of the sample. Data are presented for Pakistani and White British participants only because they form the largest ethnic groups in BiB1000 (and are relatively homogeneous) and other ethnic groups were too small for separate analysis to be reliable. No significant differences were observed between the ethnic groups with respect to BMI at booking in (approximately 12 weeks of pregnancy) or age of mothers and infants at 12-month and 18-month data collection stages.

\section{Infant intake of key indicator foods at age 12 months}

Table 3 presents the median frequency of consumption and interquartile range (IQR) for key indicator foods 
at 12 and 18 months. As expected at 12 months, consumption of commercial sweet baby foods and savoury baby foods and formula milk was minimal. Although intakes were low, the following foods featured in the diet at 12 months: chips, roast and potato shapes (1.0 (IQR 0.0-2.0) portions/week); cakes, biscuits, chocolates and sweets (0.6 (IQR 0.3-1.1) portions/d); and crisps and savoury snacks (2.0 (IQR 0.0-3.0) portions/week). Processed meat products were also eaten weekly at 12 months (0.5 (IQR $0 \cdot 0-2 \cdot 5)$ portions/week) and fruit was consumed daily (1.9 (IQR 1.1-2.7) portions/d), as were vegetables (1.7 (IQR $0 \cdot 9-2 \cdot 6)$ portions/d).

\section{Comparison of intake of key indicator foods between ages 12 and 18 months}

At 18 months the median frequency of intake of most key indicator foods had increased compared with intake at 12 months: chips, roast and potato shapes (7.0 (IQR 7.0-7.0) portions/week); cakes, biscuits, chocolates and sweets (3.0 (IQR 2.0-4.0) portions/d); crisps and savoury snacks (7.0 (IQR 7.0-7.0) portions/week); and processed meat products $(7 \cdot 0$ (IQR $0 \cdot 0-21 \cdot 0)$ portions/week). Additionally, intake of sugar-sweetened drinks (7.0 (IQR 7.0-14.0) portions/week) and pure fruit juice (7.0 (IQR 0.0-7.0) portions/week) had increased at 18 months compared with 12 months.

\section{Ethnic differences in infant intake of key indicator foods at 12 months}

Table 4 presents the associations between consumption of the key indicator foods and ethnicity when infants were aged 12 months. Odds ratios are presented for Pakistani compared with White British infants. There were a number of differences between the White British and Pakistani members of the cohort, with Pakistani infants less likely to consume any commercial savoury baby meals, more likely to consume any commercial sweet baby meals, much more likely to consume more chips or potatoes, slightly more likely to consume more vegetables, much more likely to consume more fruit, more likely to consume sugar-sweetened drinks and pure fruit juice, but much less likely to consume processed meat products than White British infants.

\section{Ethnic differences in infant intake of key indicator foods at 18 months}

The associations between consumption of the key indicator food groups at 18 months and ethnicity are shown in Table 5. Odds ratios are presented for Pakistani compared with White British infants. There were a number of differences between the White British and Pakistani infants in the cohort, with Pakistani infants less likely to consume any formula milk, processed meat products, vegetables and low-sugar drinks, but more likely to consume commercial sweet baby meals, chips, roast potatoes or potato 
Table 3 Descriptive statistics for dietary intake of key indicator food groups: whole cohort, Born in Bradford 1000 (BiB1000) study, Bradford, UK

\begin{tabular}{|c|c|c|c|c|}
\hline \multirow[b]{2}{*}{ Key indicator food group } & \multicolumn{2}{|c|}{ Intake at 12 months } & \multicolumn{2}{|c|}{ Intake at 18 months } \\
\hline & Median & IQR & Median & IQR \\
\hline Key 1: Formula milk (frequency/d) & 0.0 & $0.0-2 \cdot 0$ & 0.0 & $0.0-0.0$ \\
\hline Key 2: Commercial savoury baby foods (frequency/week) & 0.0 & $0.0-3 \cdot 0$ & 0.0 & $0.0-0.0$ \\
\hline Key 3: Commercial sweet baby foods (frequency/week) & 0.0 & $0.0-0.5$ & 0.0 & $0.0-0.0$ \\
\hline Key 4: Chips, roast and potato shapes (frequency/week) & 1.0 & $0.0-2 \cdot 0$ & $7 \cdot 0$ & $7 \cdot 0-7 \cdot 0$ \\
\hline Key 5: Processed meat products (frequency/week) & 0.5 & $0.0-2.5$ & $7 \cdot 0$ & $0.0-21 \cdot 0$ \\
\hline Key 6: Vegetables (incl. tinned and salad) (frequency/d) & 1.7 & $0.9-2.6$ & $5 \cdot 0$ & $4 \cdot 0-7 \cdot 0$ \\
\hline Key 7: Fruit (incl. fresh, tinned, cooked) (frequency/d) & 1.9 & $1 \cdot 1-2 \cdot 7$ & $5 \cdot 0$ & $4 \cdot 0-6 \cdot 0$ \\
\hline Key 8: Cakes, biscuits, chocolates and sweets (frequency/d) & 0.6 & $0 \cdot 3-1 \cdot 1$ & 3.0 & $2 \cdot 0-4 \cdot 0$ \\
\hline Key 9: Crisps and savoury snacks (frequency/week) & $2 \cdot 0$ & $0.0-3.0$ & $7 \cdot 0$ & $7 \cdot 0-7 \cdot 0$ \\
\hline Key 10: Sugar-sweetened drinks (frequency/week) & 0.0 & $0.0-5 \cdot 0$ & $7 \cdot 0$ & $7 \cdot 0-14 \cdot 0$ \\
\hline Key 11: Pure fruit juice (frequency/week) & 0.5 & $0.0-7.0$ & $7 \cdot 0$ & $0.0-7.0$ \\
\hline Key 12: Low-sugar drinks (frequency/week) & 0.0 & $0.0-1.0$ & 0.0 & $0.0-7 \cdot 0$ \\
\hline Key 13: Water (frequency/d) & 2.0 & $1.0-3.0$ & 2.0 & $1.0-4.0$ \\
\hline
\end{tabular}

$\mathrm{IQR}$, interquartile range.

shapes, fruit, crisps and savoury snacks, sugar-sweetened drinks, pure fruit juice and water than White British infants.

\section{Changes in intake between 12 and 18 months}

There were a number of differences between the White British and Pakistani members of the cohort, and these altered between the 12-month and 18-month follow-up. Pakistani members were much less likely to consume any formula milk at 18 months, whereas there was no ethnic difference at 12 months. Whereas at 12 months the Pakistani infants were much less likely to be having commercial savoury baby meals, by 18 months there was no ethnic difference. At 12 months, Pakistani infants had twice the odds of consuming an above average frequency of commercial sweet baby meals, and by 18 months the difference was fourfold. Pakistani infants continued to have twice the odds of consuming above average amounts of chips, roast potatoes or potato shapes. The tendency for Pakistani infants to consume substantially less processed meat continued at 18 months.

Whereas at 12 months Pakistani infants had slightly higher odds of consuming more than the average amount of vegetables daily, by 18 months this had decreased substantially compared with White British infants, with children of Pakistani mothers having only half the odds of above average vegetable intake. Pakistani children continued to consume more fruit than their White British counterparts, but the gap was narrower at 18 months. There continued to be little evidence of an ethnic difference in the consumption of cakes, biscuits, chocolates and sweets.

Regarding drinks, Pakistani infants continued to drink more sugar-sweetened drinks and more pure fruit juice than their White British counterparts, with the gap widening. Moreover, whereas at 12 months there was no difference in consumption of low-sugar drinks, White
British infants at 18 months had twice the odds of consuming above average amounts than Pakistani infants. While there was no difference in consumption of water at 12 months, by 18 months the Pakistani infants were reported to have at least three times the odds of consuming water alone compared with White British infants.

\section{Discussion}

The present study indicated that, at 12 months, there was already evidence of the early introduction of foods high in sugar and fat. Foods such as chips, roast and potato shapes; cakes, biscuits, chocolates and sweets; crisps and savoury snacks; and processed meat products featured regularly in the diets of infants. Analysis of the diet at 18 months revealed a substantial increase in the frequency of consumption of these same foods. Of particular concern was the increase observed at 18 months in the intake of sugar-sweetened drinks, which are associated with the development of obesity ${ }^{(24)}$.

Of particular interest are the ethnic differences in intake of key indicator foods observed in our sample of White British and Pakistani infants at 12 and 18 months. Our study has shown ethnic differences in dietary intake as early as 12 months and that these differences persist at 18 months. At 12 months Pakistani infants were less likely to consume commercial savoury baby foods and processed meat products and more likely to consume commercial sweet baby foods, chips or roast potatoes, vegetables, fruit, sugar-sweetened drinks and pure fruit juice than White British infants. By 18 months these differences were shown to persist and increase in magnitude. At 18 months there was a fourfold difference in consuming an above average frequency of commercial sweet baby foods compared with a twofold difference at 12 months. Pakistani toddlers continued to consume more chips, roast 


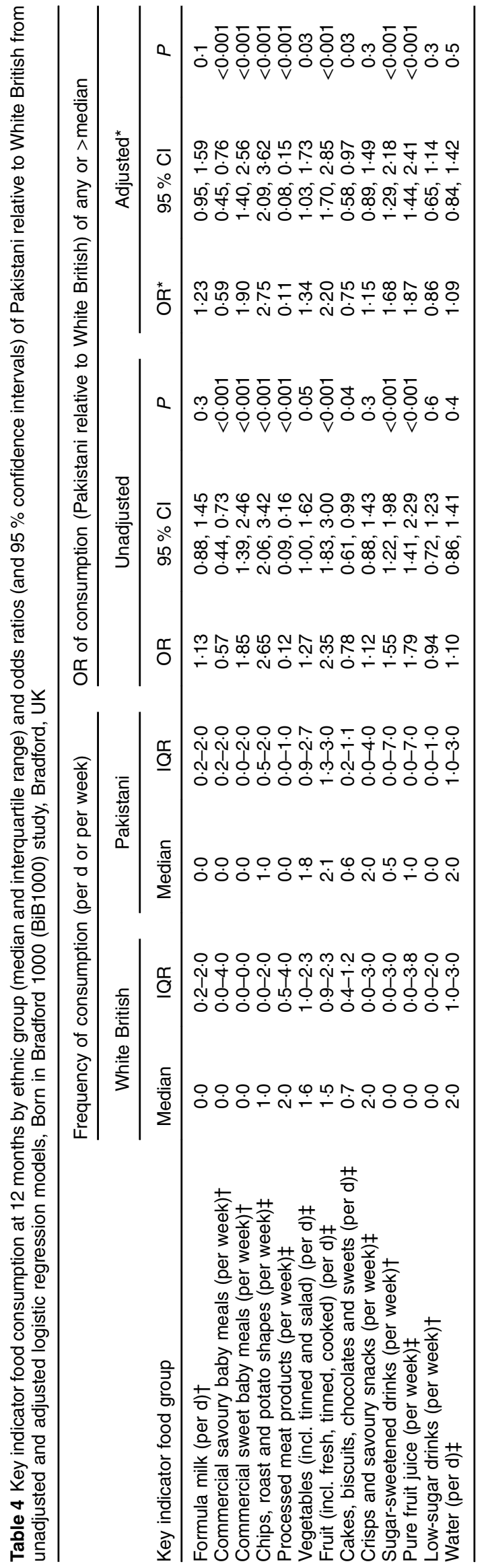

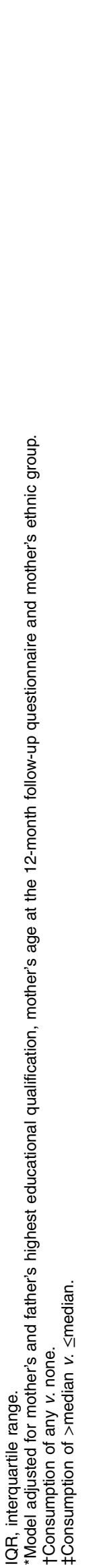

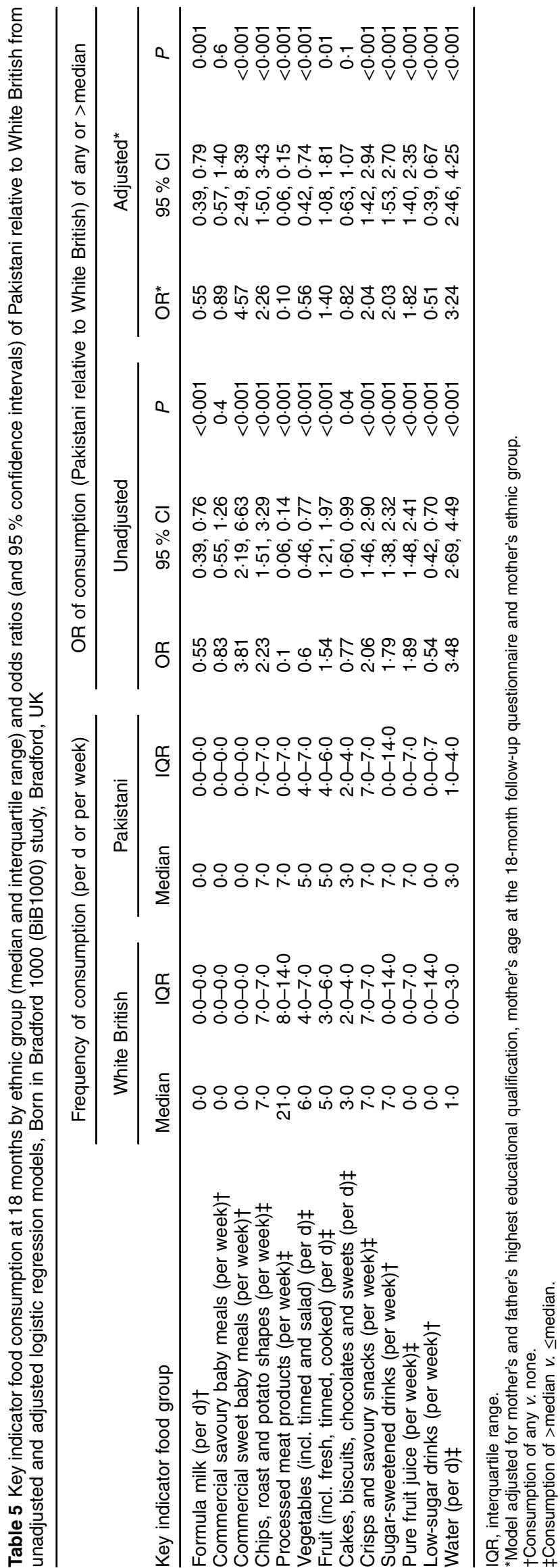


potatoes or potato shapes, more fruit and substantially less processed meat products at 18 months. Regarding drinks, Pakistani children continued to drink increasingly more sugar-sweetened drinks, more pure fruit juice and more water than White British toddlers. However, White British toddlers consumed more low-sugar drinks.

The present study considered the associations between dietary intake of key indicator foods and ethnicity within a cohort of White British and Pakistani infants at age 12 and 18 months. Other studies have explored ethnic differences in dietary intake and feeding patterns; however, these were in older children and not in South Asian infants ${ }^{(25-27)}$. Furthermore, to our knowledge, the present study is first that examines ethnic differences in the types of foods consumed during infancy with follow-up assessment in early toddlerhood. Findings suggest that ethnicity is associated with early dietary intake and some important trends were found in dietary intake of infants between 12 and 18 months.

Infant feeding practices have been shown to be associated with ethnicity. Higher breast-feeding initiation rates among other ethnic groups compared with White British mothers are well documented ${ }^{(28)}$ and Pakistani mothers are more likely to initiate breast-feeding and breast-feed for longer compared with White British mothers ${ }^{(29)}$. Although there is also some evidence of ethnic differences in age of weaning suggesting that White mothers introduce solids earlier than mothers of Asian origin ${ }^{(28,30,31)}$, limited evidence exists on the types of foods consumed during infancy within these groups.

Epidemiological evidence suggests that early-life factors influence later life ${ }^{(32)}$ and that the diet of infants and toddlers has short- and long-term implications for health and development ${ }^{(12)}$. Furthermore, it has been suggested that dietary patterns emerge early ${ }^{(8)}$ and track through infancy $^{(9)}$ into later childhood ${ }^{(10)}$ and then into adulthood $^{(11)}$. There are therefore several implications from our study. During infancy and early childhood, infant feeding practices and the child's diet are among the risk factors associated with the development of obesity. As infancy represents the most rapid change in diet over the life course and is the period when dietary preferences and habits are first established ${ }^{(9)}$, it is important to understand what infants are eating and whether this conforms to healthy eating patterns. The current study has contributed to the limited evidence base by presenting data on early food intake, highlighted the presence of high-energydensity foods in the diets of infants as early as 12 months and demonstrated evidence of tracking of these early intake patterns.

Understanding and characterizing these differences can help inform the design of clinical and public health interventions and policies to reduce the prevalence of childhood obesity and eliminate disparities among ethnic minority children. Current evidence supports that consumption of sugar-sweetened beverages contributes significantly to obesity ${ }^{(33-35)}$. Data from interventions targeting a reduction in sugar-sweetened beverages indicate significant reductions in BMI compared with control groups ${ }^{(36,37)}$. Data from the present study have highlighted the early consumption of sugar-sweetened drinks which increases with age for all infants, with particularly higher intake among Pakistani infants. The restriction of sugarsweetened drinks should therefore constitute a key message for early interventions aimed at promoting and establishing healthy infant dietary behaviours. For Pakistani infants reduced dependence on sweet commercial baby foods and moderation in consumption of high-fat foods such as chips and roast potatoes should be recommended, whereas a reduction of processed meat products should a recommendation for White British infants. Parents play an important role in food provision and feeding practices, acting as role models for eating behaviours and food intakes ${ }^{(38-40)}$. Furthermore, due to the evidence of early tracking of dietary intake patterns, interventions should therefore begin during the antenatal period so that parents are encouraged to reflect on the family diet and eating patterns in preparation for the birth of their baby.

By the pre-school years ethnic disparities in obesity prevalence are already present, suggesting that disparities in childhood obesity prevalence may have their origins in the earliest stages of life ${ }^{(41)}$. It is considered that ethnic differences in early-life risk factors for obesity might contribute to the high prevalence of obesity among minority children of pre-school age and beyond. By comparing dietary intake between Pakistani and White British infants, the present study has been able to characterize early-life dietary intake and understand the influence of ethnicity on intake patterns.

The present findings not only help to characterize early dietary intake, but will also help to understand intake patterns of Pakistani and White British infants in order to examine how early diet influences later health outcomes including weight outcomes. Further research is required to establish the influence of these dietary patterns during infancy on later health outcomes including weight outcomes and also in other ethnic groups.

Strengths of the study include a large bi-ethnic sample; the data were collected longitudinally at 12 and 18 months by trained multilingual community researchers. Similar to other cohort studies ${ }^{(42-44)}$, dietary data in BiB1000 were collected by parent-reported FFQ. This method is prone to overestimate intake but is a standard, feasible approach in large samples ${ }^{(45)}$. Further, a validated questionnaire was used $^{(22)}$ and to our knowledge, there is no systematic error in reporting within FFQ by ethnicity ${ }^{(25)}$. The sample within the current study was limited to White British and Pakistani infants and toddlers. It is recognized that this constitutes only one South Asian group and therefore, due to the heterogeneous nature of this ethnic group, the data cannot be generalized to other South Asian infants. Further exploration 
of dietary intake in this age group is warranted for other ethnic groups including other South Asian groups.

\section{Conclusion}

The food intake patterns of White British and Pakistani infants are not well documented. Our study has shown that intake of food groups high in fat and sugar is evident in the diets of all infants as early as 12 months of age and that the consumption frequency of these foods increases in toddlers aged 18 months. Furthermore, ethnic differences in consumption patterns are evident in White British and Pakistani infants at 12 months and these differences persist and increase by 18 months of age.

These data help to characterize early diet during infancy, suggesting that unhealthy diets linked with obesity development are established very early in life. New evidence is also presented about early ethnic differences in dietary intake. This information should be used to inform the development of community-tailored and culturally adapted obesity prevention interventions in South Asian populations. The data also help to characterize early-life dietary intake and help understand the composition of such patterns in order to examine how early diet influences later health outcomes. Further research is required to establish the influence of these dietary patterns in infancy and early toddlerhood on later health outcomes, including childhood obesity, across other ethnic groups.

\section{Acknowledgements}

Acknowledgements: The authors wish to acknowledge Paul Slade (database manager); Gill Santorelli (statistician); all of the children and parents in $\mathrm{BiB}$; and the health professionals and $\mathrm{BiB}$ research team. Financial support: This paper presents independent research commissioned by the National Institute for Health Research (NIHR) under its Programme Grants for Applied Research Programme (grant number RP-PG-0407-10044). The Dietary Analysis element was funded by The Learning Curve Grant 2011 from Danone Baby Nutrition. The views expressed are those of the author(s) and not necessarily those of the National Health Service, the NIHR, the Department of Health or Danone. Conflict of interest: None. Authorship: P.S. designed the dietary analysis study; D.C.G. contributed to the analysis plan and undertook the statistical analysis; L.A.G. contributed to the data analysis. All authors contributed to the interpretation of the results and write-up, and have read and approved the final version. Ethics of buman subject participation: Ethical approval was granted by Bradford Research Ethics Committee (Ref 07/H1302/112) and all participants provided written informed consent (including allowing access to routine data collection) prior to inclusion in the research.

\section{References}

1. World Health Organization (2000) Obesity: Preventing and Managing the Global Epidemic. Report of a WHO Consultation. WHO Technical Report Series no. 894, Geneva: WHO.

2. Wang Y \& Lobstein T (2006) Worldwide trends in childhood overweight and obesity. Int J Pediatr Obes 1, 11-25.

3. Department of Health (2009) Healthy Weight, Healthy Lives: One Year On. http://webarchive.nationalarchives.gov.uk/ 20100407220245/http://www.dh.gov.uk/prod_consum_dh/ groups/dh_digitalassets/documents/digitalasset/dh_097623. pdf (accessed November 2013).

4. Health and Social Care Information Centre (2013) National Child Measurement Programme: England, 2012/13 school year. http://www.hscic.gov.uk/catalogue/PUB13115/nati-chilmeas-prog-eng-2012-2013-rep.pdf (accessed February 2014).

5. Saxena S, Ambler G, Cole TJ et al. (2004) Ethnic group differences in overweight and obese children and young people in England: cross sectional survey. Arch Dis Child 89, 30-36.

6. Razak F, Anand SS, Shannon H et al. (2007) Defining obesity cut points in a multiethnic population. Circulation $\mathbf{1 1 5}$, 2111-2118.

7. Singhal A, Fewtrell M, Cole TJ et al. (2003) Low nutrient intake and early growth for later insulin resistance in adolescents born preterm. Lancet 361, 1089-1097.

8. Smithers LG, Brazionis L, Golley RK et al. (2012) Associations between dietary patterns at 6 and 15 months of age and sociodemographic factors. Eur J Clin Nutr 66, 658-666.

9. Robinson S, Marriott L, Poole J et al. (2007) Dietary patterns in infancy: the importance of maternal and family influences on feeding practice. Br J Nutr 98, 1029-1037.

10. Northstone K \& Emmett P (2013) The associations between feeding difficulties and behaviours and dietary patterns at 2 years of age: the ALSPAC cohort. Matern Child Nutr $\mathbf{9}$, $533-542$

11. Mikkila V, Rasanen L, Raitakari OT et al. (2005) Consistent dietary patterns identified from childhood to adulthood: the cardiovascular risk in Young Finns Study. Br J Nutr $\mathbf{9 3}$, 923-931.

12. Smithers LG, Golley RK, Brazionis L et al. (2011) Characterizing whole diets of young children from developed countries and the association between diet and health: a systematic review. Nutr Rev 69, 449-467.

13. Moorcroft KE, Marshall JL \& McCormick FM (2011) Association between timing of introducing solid foods and obesity in infancy and childhood: a systematic review. Matern Child Nutr 7, 3-26.

14. Birch L, Savage JS \& Ventura A (2007) Influences on the development of children's eating behaviours: from infancy to adolescence. Can J Diet Pract Res 68, 1-56.

15. Barker DJP (2007) Obesity and early life. Obes Rev $\mathbf{8}$, Supp. 1, 45-49.

16. Ponza M, Devaney B, Ziegler P et al. (2004) Nutrient intakes and food choices of infants and toddlers participating in WIC. J Am Diet Assoc 104, Suppl. 1, S71-S79.

17. Northstone K, Rogers I, Emmett P et al.; ALSPAC Study Team (2002) Drinks consumed by 18-month-old children: are current recommendations being followed? Eur J Clin Nutr 56, 236-244.

18. Department of Health (2013) Diet and Nutrition Survey of infants and young children, 2011. https://www.gov.uk/ government/publications/diet-and-nutrition-survey-of-infantsand-young-children-2011 (accessed May 2014).

19. Wright J, Small N, Raynor P et al. (2013) Cohort profile: the Born in Bradford multi-ethnic family cohort study. Int $J$ Epidemiol 42, 978-991.

20. Raynor P \& Born in Bradford Collaborative Group (2008) Born in Bradford, a cohort study of babies born in Bradford, 
and their parents: protocol for the recruitment phase. $B M C$ Public Health 23, 327-339.

21. Bryant M, Santorelli G, Fairley L et al.; Born in Bradford Childhood Obesity Scientific Group (2013) Design and characteristics of a new birth cohort to study the early origins of childhood obesity: the BiB1000 study. Longit Life Course Stud 4, 119-135.

22. Marriott LD, Inskip HM, Borland SE et al.; Southampton Women's Study Group (2008) What do babies eat? Evaluation of a food frequency questionnaire to assess the diets of infants aged 12 months. Public Health Nutr 12, 967-972.

23. City of Bradfrod Metropolitan District Council (2012) 2011 Census results. www.bradford.gov.uk/bmdc/government_ politics_and_public_administration/2011_census (accessed August 2013).

24. Salvo D, Frediani JK, Ziegler TR et al. (2012) Food group intake patterns and nutrient intake vary across low-income Hispanic and African American preschool children in Atlanta: a cross sectional study. Nutr J 11, 62-70.

25. De Hoog MLA, Kleinman KP, Gillman MW et al. (2014) Racial/ethnic and immigrant differences in early childhood diet quality. Public Health Nutr 17, 1308-1317.

26. Perrin EM, Rothman RL, Sanders LM et al. (2014) Racial and ethnic differences associated with feeding- and activityrelated behaviors in infants. Pediatrics 133, e857-e867.

27. Ludwig DS, Peterson KE \& Gortmaker SL (2001) Relation between consumption of sugar-sweetened drinks and childhood obesity: a prospective, observational analysis. Lancet 357, 505-508.

28. NHS Information Centre for Health and Social Care (2012) Infant feeding survey - 2010. http://www.data.gov.uk/data/ search?q=infant+feeding+ (accessed March 2013).

29. Kelly YJ, Watt RG \& Nazroo JY (2006) Racial/ethnic differences in breastfeeding initiation and continuation in the United Kingdom and comparison with findings in the United States. Pediatrics 118, 1428-1435.

30. Griffiths LJ, Tate AR \& Dezateux C (2007) Do early infant feeding practices vary by maternal ethnic group? Public Health Nutr 10, 957-964.

31. Thomas M \& Avery V (1997) Infant Feeding in Asian Families. Report no. 3759. London: The Stationery Office.

32. Lynch JW \& Smith GD (2005) A life-course approach to chronic disease epidemiology. Annu Rev Public Health 26, $1-35$.
33. Pereira MA (2006) The possible role of sugar-sweetened beverages in obesity etiology: a review of the evidence. Int $J$ Obes (Lond) 30, Suppl. 3, S28-S36.

34. Malik VS, Schulze MB \& Hu FB (2006) Intake of sugarsweetened beverages and weight gain: a systematic review. Am J Clin Nutr 84, 274-288.

35. Malik VS, Willett WC \& Hu FB (2009) Sugar-sweetened beverages and BMI in children and adolescents: reanalyses of a meta-analysis. Am J Clin Nutr 89, 438-439.

36. Sichieri R, Yokoo EM, Pereira RA et al. (2013) Water and sugar-sweetened beverage consumption and changes in BMI among Brazilian fourth graders after 1-year follow-up. Public Health Nutr 16, 73-77.

37. James J, Thomas P, Cavan D et al. (2004) Preventing childhood obesity by reducing consumption of carbonated drinks: cluster randomised controlled trial. BMJ 328, 1237.

38. van der Horst K, Oenema A, Ferreira I et al. (2007) A systematic review of environmental correlates of obesity-related dietary behaviors in youth. Health Educ Res 22, 203-226.

39. Pearson N, Biddle SJ \& Gorely T (2009) Family correlates of fruit and vegetable consumption in children and adolescents: a systematic review. Public Health Nutr 12, 267-283.

40. Campbell K, Hesketh K \& Davison KK (2010) The role of parents in preventing child overweight and obesity: an ecological approach. In Obesity Epidemiology. From Aetiology to Public Health, 2nd ed., pp. 299-320 [D Crawford, RW Jeffery, K Ball et al., editors]. Oxford: Oxford University Press.

41. Dixon B, Pena MM \& Taveras EM (2012) Lifecourse approach to racial/ethnic disparities in childhood obesity. Adv Nutr 3, 73-82.

42. Robinson SM, Marriott LD, Crozier SR et al. (2009) Variations in infant feeding practice are associated with body composition in childhood: a prospective cohort study. J Clin Endocrinol Metab 94, 2799-2805.

43. Emmett P (2009) Dietary assessment in the Avon Longitudinal Study of Parents and Children. Eur J Clin Nutr 63, Suppl. 1, S38-S44.

44. Leventakou V, Georgiou V, Chatzi L et al. (2015) Relative validity of an FFQ for pre-school children in the motherchild 'Rhea' birth cohort in Crete, Greece. Public Health Nutr 18, 421-427.

45. Cade J, Thompson R, Burley V et al. (2002) Development, validation and utilisation of food-frequency questionnaires a review. Public Health Nutr 5, 567-587. 